\title{
Correction to: Assessing the effects of Farmer Field Schools on farmers' trajectories of change in practices
}

\author{
Teatske Bakker ${ }^{1,2}$ (1) $\cdot$ Patrick Dugué ${ }^{1,2} \cdot$ Stéphane de Tourdonnet ${ }^{3}$
}

Accepted: 5 March 2021 / Published online: 29 March 2021

(C) INRAE and Springer-Verlag France SAS, part of Springer Nature 2021

\section{Correction to: Agronomy for Sustainable Development} https://doi.org/10.1007/s13593-021-00667-2

During the publication process of above mentioned article the titles of figures 2 and 3 were erroneously deleted from the figure captions. Figures 2 and 3 with revised figure captions are given below.

The original article has been corrected.

Publisher's note Springer Nature remains neutral with regard to jurisdictional claims in published maps and institutional affiliations.

The online version of the original article can be found at https://doi.org/ 10.1007/s13593-021-00667-2

Teatske Bakker

teatske.bakker@cirad.fr

CIRAD, UMR INNOVATION, F-34398 Montpellier, France

2 University of Montpellier, F-34090 Montpellier, France

3 INNOVATION, University of Montpellier, CIRAD, INRAE, Institut Agro, Montpellier, France 


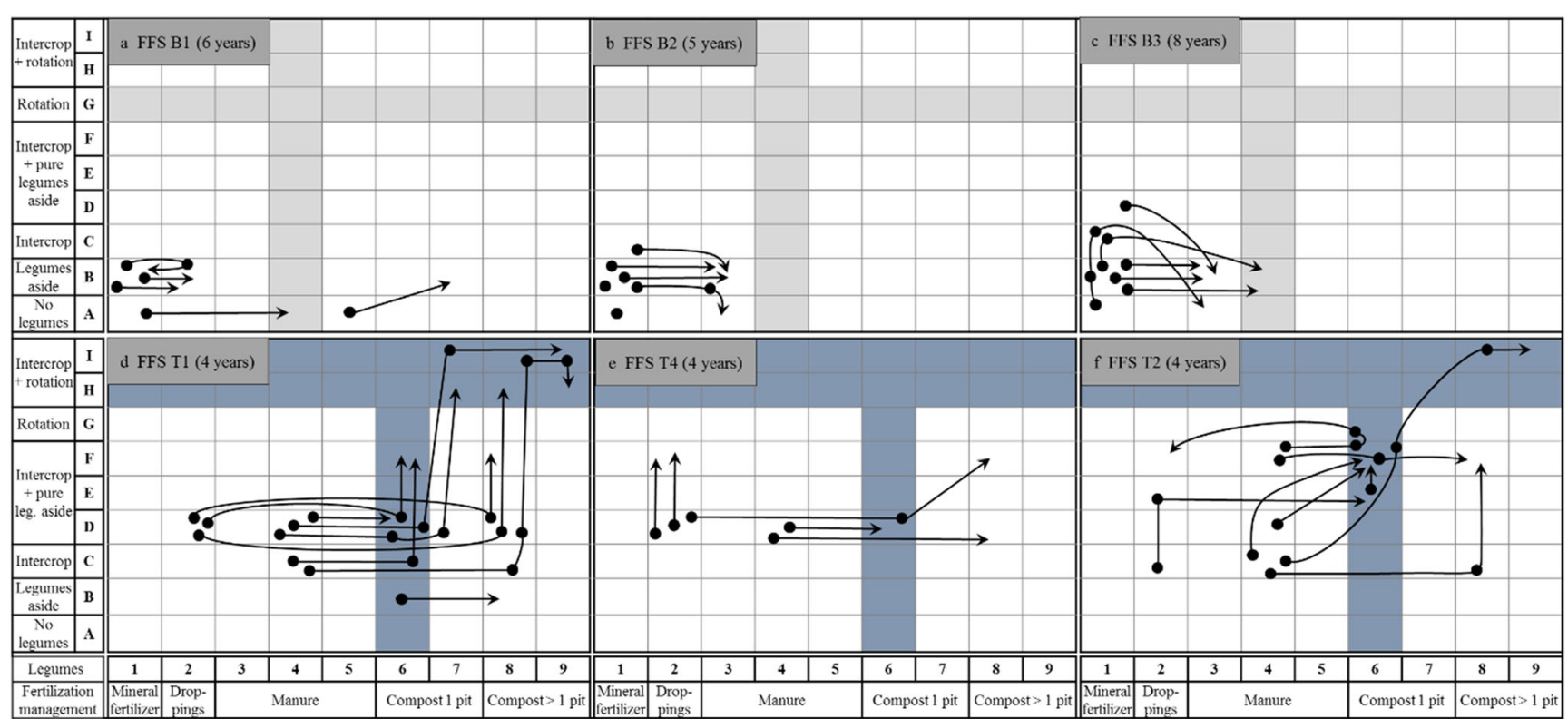

Fig. 2 Farmers' trajectories of change in agricultural practices after Farmer Field Schools for rainy season crops in 3 consultative FFS in western Burkina Faso (top line: block a, b, c) and 3 collaborative FFS in northern Togo (bottom line: block d, e, f). The grey boxes display the FFS code described in table 1 and the time span between the start of the FFS and the survey. The scaling and codes for the two axis on legume cropping and fertilization management practices are described in table 2.b. The practices implemented within the FFS plots are highlighted in the rows and columns in light grey (consultative FFS, Burkina Faso) and dark grey (collaborative FFS, Togo). Each trajectory represents one individual farmer. The first black dot represents the farmer's practice at the beginning of the participation to the FFS, the following dots (if there are any) represent the successive changes in practices made by the farmer according the survey, and the arrow represents the last change in practices made at the time of interviewing. The dots do not correspond to each cropping season, only to the successive changes in practices made by farmers. 


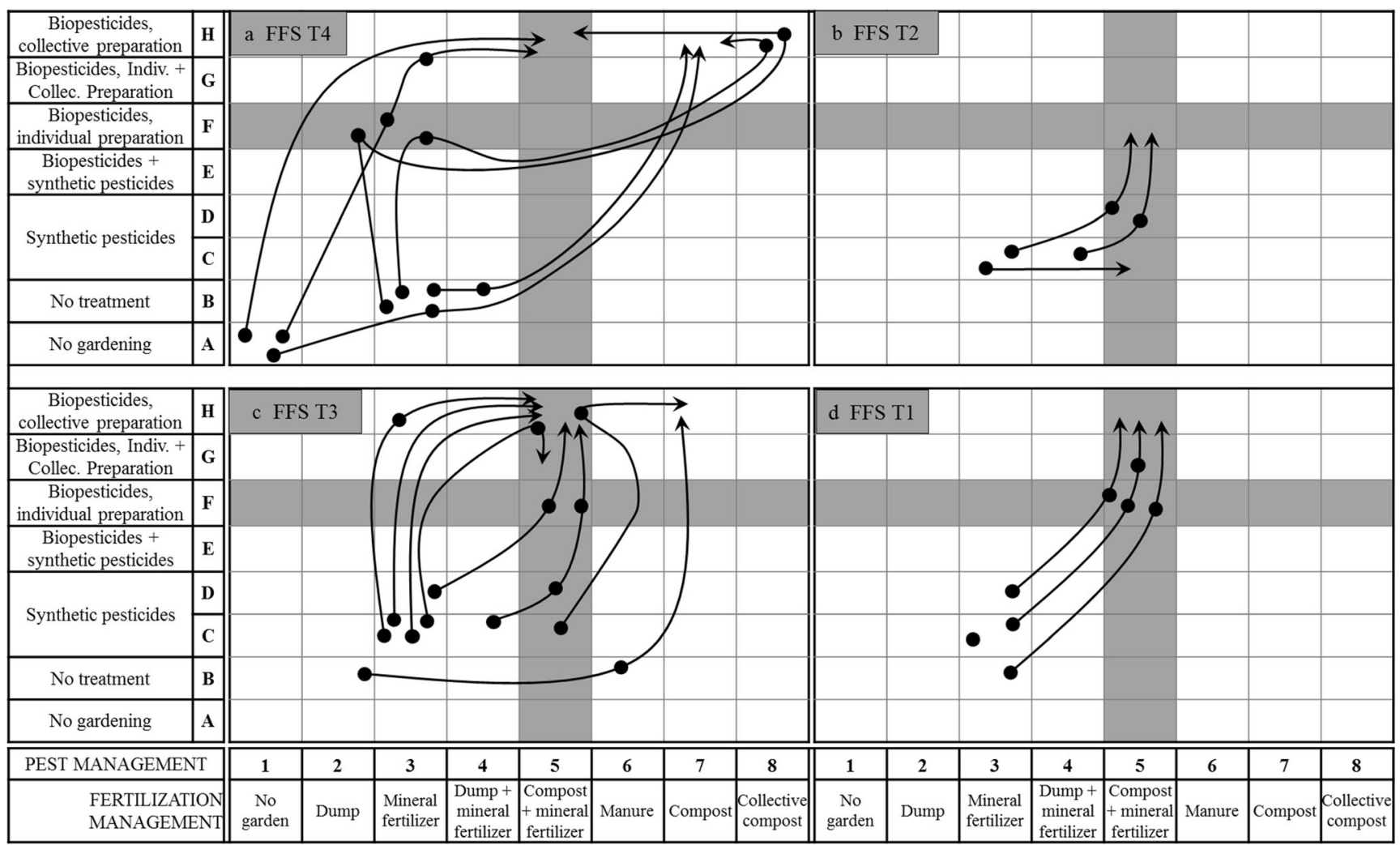

Fig. 3 Farmers' trajectories of change in practices after Farmer Field Schools for vegetable gardening in $\mathbf{4}$ collaborative FFS in northern Togo. The grey boxes display the FFS code described in table1. The scaling and codes for the two axis on legume cropping and fertilization management practices are described in table 2.a. The rows and columns in grey highlight the practices implemented within the FFS plots. The time span between the start of the FFS and the survey is 5 years for all represented FFS.Each trajectory represents one individual farmer. The first black dot represents the farmer's practice at the beginning of the participation to the FFS, the following dots (if there are any) represent the successive changes in practices made by the farmer according the survey, and the arrow represents the last change in practices made at the time of interviewing. The dots do not correspond to each cropping season, only to the successive changes in practices made by farmers. 